\title{
Nanomechanical and Macrotribological Properties of CVD-Grown Graphene as a Middle Layer between Metal Pt Cylinders and $\mathrm{SiO}_{2} / \mathrm{Si}$ Substrate
}

\author{
Hongyan Wu, ${ }^{1,2,3}$ Zhengbin Gu, $^{1}$ Shantao Zhang, ${ }^{1}$ and G. Hussain ${ }^{4}$ \\ ${ }^{1}$ National Laboratory of Solid State Microstructures and Department of Materials Science and Engineering, \\ Nanjing University, Nanjing 210093, China \\ ${ }^{2}$ Department of Material Physics, Nanjing University of Information Science and Technology, Nanjing 210044, China \\ ${ }^{3}$ Department of Civil and Environmental Engineering, University of Missouri-Columbia, Columbia, MO 65211, USA \\ ${ }^{4}$ Department of Mechanical Engineering, GIK Institute of Engineering Sciences \& Technology, Topi, \\ Khyber Pakhtunkhwa 23460, Pakistan
}

Correspondence should be addressed to Hongyan Wu; wuho@missouri.edu and Zhengbin Gu; zbgu@nju.edu.cn

Received 2 September 2015; Accepted 7 October 2015

Academic Editor: Ungyu Paik

Copyright ( $\odot 2015$ Hongyan Wu et al. This is an open access article distributed under the Creative Commons Attribution License, which permits unrestricted use, distribution, and reproduction in any medium, provided the original work is properly cited.

The CVD-grown graphene as a middle layer was introduced between $\mathrm{Pt}$ cylinders and $\mathrm{SiO}_{2} / \mathrm{Si}$ to extend the application of graphene for improving the wear performance of microelectromechanical systems. Periodic arrays of Pt cylinders were prepared on the graphene $/ \mathrm{SiO}_{2} / \mathrm{Si}\left(\mathrm{Pt} /\right.$ graphene) and $\mathrm{SiO}_{2} / \mathrm{Si}$ substrate $\left(\mathrm{Pt} / \mathrm{SiO}_{2}\right)$ using the magnetron sputtering technique. To characterize $\mathrm{Pt} /$ graphene and $\mathrm{Pt} / \mathrm{SiO}_{2}$, nanoindentation and macrotribological tests were performed. The results showed that the friction coefficient was lower and the wear lifetime of Pt/graphene was longer than those of $\mathrm{Pt} / \mathrm{SiO}_{2}$. Graphene, as a middle layer, was not only observed to have significant influence on the mechanical properties (i.e., microhardness and elastic modulus), but also found to improve the adhesive strength between $\mathrm{SiO}_{2} / \mathrm{Si}$ and Pt cylinders.

\section{Introduction}

The two-dimensional graphene is a solid lubricant which stacks in a lamellar structure with low shear strength similar to graphite; and also being the thinnest lubricant it remains chemically stable even under extreme environmental conditions [1]. Owing to these characteristics, graphene exhibits superior frictional properties both at atomic and at molecular scales $[2,3]$.

It is well established fact that graphene offers excellent tribological performance at nano/micro level $[4,5]$. Nowadays, a great deal of effort is being spent to investigate its macrotribological behavior. Recent studies have shown that graphene grown by chemical vapor deposition (CVD) and the assembled reduced graphene oxide (RGO) developed by the oxidation reduction method $[6,7]$ have potential to be employed as a lubricant in order to protect the substrate surface under severe loading conditions. In another study by the authors [8], it has been demonstrated that the array of Pt cylinders on CVD-grown graphene further improves its macrotribological properties. Because CVD-grown graphene is always transferred onto the $\mathrm{SiO}_{2} / \mathrm{Si}$ surfaces, the mechanical properties of graphene as a middle layer between $\mathrm{Pt}$ and $\mathrm{SiO}_{2}$ film on macrotribological properties of $\mathrm{SiO}_{2} / \mathrm{Si}$ substrate were not clarified.

The $\mathrm{Si}$ and $\mathrm{SiO}_{2}$ surfaces have found various important applications in microelectromechanical systems. The Pt cylinders can be deposited on these surfaces to improve their tribological properties and affect the surface energy of the surface. However, Pt exhibits poor adhesion to these surfaces. This issue can be resolved using middle layers (typical thickness of $10-20 \mathrm{~nm}$ ) such as titanium (Ti) at the interface between $\mathrm{SiO}_{2} / \mathrm{Si}$ substrates and $\mathrm{Pt}$ [9]. Alternatively, graphene can also be used as a middle layer. In fact, the carbon vacancies on a graphene sheet enhance the Pt-graphene interaction [10]. Okazaki-Maeda et al. [11] have calculated 
the interactions between $\mathrm{Pt}$ and a graphene sheet by firstprinciples. They have proposed that the interface becomes stable as the number of $\mathrm{Pt}$ atoms increases, a form of threedimensional (3D) planar configurations. Their results also indicate that the interconnected flexible network of graphene has a certain cohesive energy with $\mathrm{SiO}_{2} / \mathrm{Si}$ substrate due to the existence of the oxygen defects in $\mathrm{a} i O_{2}$ surface.

The above discussion follows that introduction of graphene as a middle layer can improve bonding between $\mathrm{Pt}$ and $\mathrm{SiO}_{2} / \mathrm{Si}$ substrate, and as a result the macrotribological properties of $\mathrm{SiO}_{2} / \mathrm{Si}$ substrate can be improved. The current work is an attempt in this direction. The nanomechanical properties and macrotribological behavior of $\mathrm{Pt} / \mathrm{SiO}_{2}$ and $\mathrm{Pt} /$ graphene were investigated carefully. Additionally, the interaction effects between graphene and Pt cylinders were also discussed by nanoindentation tests and the contact angle analysis. The surface morphologies and composition at the center of the wear track of $\mathrm{Pt} / \mathrm{SiO}_{2}$ and $\mathrm{Pt}$ /graphene were analyzed by scanning electron microscopy (SEM) and Raman spectra.

\section{Experimental and Methods}

2.1. Preparation of Graphene and Metal Pt Cylinder-Array Structures. Graphene was prepared on $\mathrm{Cu}$ foils $(20 \times 20 \times$ $0.025 \mathrm{~mm})$ by CVD in a 5 -inch quartz tube. $\mathrm{H}_{2}(10 \mathrm{sccm})$ gas was made to flow for $30 \mathrm{~min}$ so as to clean and reduce the $\mathrm{Cu}$ foils. To generate a carbon source at $1000^{\circ} \mathrm{C}, \mathrm{CH}_{4}(65 \mathrm{sccm})$ was made to flow for $15 \mathrm{~min}$ to provide the carbon source. After growing graphene on $\mathrm{Cu}$ foils, polymethylmethacrylate (PMMA) was used as a supporting layer to protect the synthesized graphene during the etching process. The $\mathrm{Cu}$ catalyst was removed by $0.5 \mathrm{~mol} / \mathrm{L}$ ferrous trichloride solution, followed by rinsing with deionized water. Then graphene was transferred to the $\mathrm{SiO}_{2} / \mathrm{Si}$ substrate (graphene/ $/ \mathrm{SiO}_{2} / \mathrm{Si}$ ) following the method reported in [8].

After the graphene is transferred onto the $\mathrm{Si} / \mathrm{SiO}_{2}$ substrate, a metal shadow mask with cylinder-array holes was laid on the top of $\mathrm{Pt} / \mathrm{SiO}_{2}$ and $\mathrm{Pt} /$ graphene. This was done employing magnetron sputtering following the method reported in the literature [8]. The periodic arrays of $\mathrm{Pt}$ cylinders were separately fabricated on the $\mathrm{SiO}_{2} / \mathrm{Si}$ substrate and graphene $/ \mathrm{SiO}_{2} / \mathrm{Si}$, as depicted in Figure 1 . Figure 1 shows the surface morphologies of a triangular array of Pt cylinders on (a) $\mathrm{SiO}_{2} / \mathrm{Si}$ substrate and (b) graphene $/ \mathrm{SiO}_{2} / \mathrm{Si}$.

2.2. Nanoindentation and Surface Characteristics. The nanoindentation experiments on $\mathrm{Pt} /$ graphene and $\mathrm{Pt} / \mathrm{SiO}_{2}$ were carried out with the continuous stiffness measurement (CSM), which was configured with a Berkovich (3-sided pyramid) diamond tip. The test was measured at a loading rate of $4-40 \mathrm{mN} / \mathrm{min}$. The load range was $2 \sim 20 \mathrm{mN}$, and the holding time was $10 \mathrm{~s}$. The nanoindentation experiments for both $\mathrm{Pt}$ /graphene and $\mathrm{Pt} / \mathrm{SiO}_{2}$ were carried out randomly on the surface of Pt cylinders for five times and then both the average microhardness and elastic modulus were obtained.

The water contact angle (WCA) of graphene and $\mathrm{SiO}_{2} / \mathrm{Si}$ was measured to determine surface energy measurements using a contact angle meter (DSA100, Kruss, Germany). In order to provide statistical means, at least four measurements on each sample were carried out and an average of these values was used.

The surface adhesive forces between graphene and $\mathrm{SiO}_{2} / \mathrm{Si}$ substrate were measured using a friction force microscope (FFM). Square pyramidal silicon nitride $\left(\mathrm{Si}_{3} \mathrm{~N}_{4}\right)$ tips (tip radius $\sim 50 \mathrm{~nm}$ ) were used on a cantilever with a stiffness of $2 \mathrm{~N} / \mathrm{m}$. The pull-off force was considered to be the adhesive force. The adhesive force test on each sample was conducted for ten times to obtain an average adhesive force.

\subsection{Macrotribological Tests and Surface Characteristics.} Macrotribological tests were run employing a UMT-2MT tribometer (CETR) in a ball-on-plate contact configuration under the testing conditions of $0.1 \mathrm{~N}$ normal force and $1 \mathrm{~Hz}$ frequency. GCr15 steel balls (diameter, $6 \mathrm{~mm}$, and mean roughness, $0.02 \mu \mathrm{m}$ ) were used as the stationary upper counter-bodies, and $\mathrm{Pt} / \mathrm{SiO}_{2}$ and $\mathrm{Pt} /$ graphene were mounted onto the flat base and driven to reciprocating motion at a distance of $0.5 \mathrm{~cm}$. The friction coefficients versus time curves were generated automatically. All experiments were performed under ambient conditions of $25^{\circ} \mathrm{C}$ and $26 \%$ relative humidity.

The wear morphologies of $\mathrm{Pt} /$ graphene and $\mathrm{Pt} / \mathrm{SiO}_{2}$ were characterized by SEM (JEOL JSM-6300). Raman spectra (Labram HR800 Jobin Yvon) of the samples were measured using $514 \mathrm{~nm}$ laser excitation. The measurements for each sample were carried out for three times from three different locations so as to obtain average data.

\section{Results and Discussions}

3.1. Nanoindentation of the Pt Cylinder-Array Structure. The effect of graphene as a middle layer on interface between $\mathrm{Pt}$ and $\mathrm{SiO}_{2} / \mathrm{Si}$ was evaluated by analyzing the indentation load-depth curve. Figures 2(a) and 2(b) illustrate the loaddisplacement curves for $\mathrm{Pt} / \mathrm{SiO}_{2}$ and $\mathrm{Pt} /$ graphene under different loads. As can be seen from Figure 2(a), there is a sudden breakdown (or pop-in) in the displacement curve of $\mathrm{Pt} / \mathrm{SiO}_{2}$ corresponding to $2 \mathrm{mN}$ load $70 \mathrm{~nm}$ depth. This indicates that the fracture at the $\mathrm{Pt} / \mathrm{SiO}_{2}$ surface can take place, due to a burst of strain accompanied by the transition from purely elastic behavior to plastic behavior [12]. Contrarily, the pop-in effect is not present on the $\mathrm{Pt}$ /graphene curve, except a slight inflexion around the depth of $70 \mathrm{~nm}$ as illustrated in Figure 2(b). This follows that the mechanical damage at the $\mathrm{Pt} /$ graphene interface is lighter than that at the $\mathrm{Pt} / \mathrm{SiO}_{2}$ interface. Furthermore, as obvious from the load-displacement curves, $\mathrm{Pt} /$ graphene experiences higher indentation depth than the $\mathrm{SiO}_{2} / \mathrm{Si}$ does which reflects the effect of graphene film on Pt cylinders. Because the thickness of the Pt cylinder is approximately $100 \mathrm{~nm}$, the popin displacement $(70 \mathrm{~nm})$ is more than $10-20 \%$ of a thin-film thickness. As reported in the literature [13], the results are obviously affected by the $\mathrm{SiO}_{2}$ or graphene.

For the present systems, like a soft film $(\mathrm{Pt})$ on a hard substrate (i.e., graphene/ $\mathrm{SiO}_{2} / \mathrm{Si}$ and $\mathrm{SiO}_{2} / \mathrm{Si}$ ), the interaction at the film-substrate interface can be analyzed by the depth sensing nanoindentation measurements [14]. Figure 2(c) 


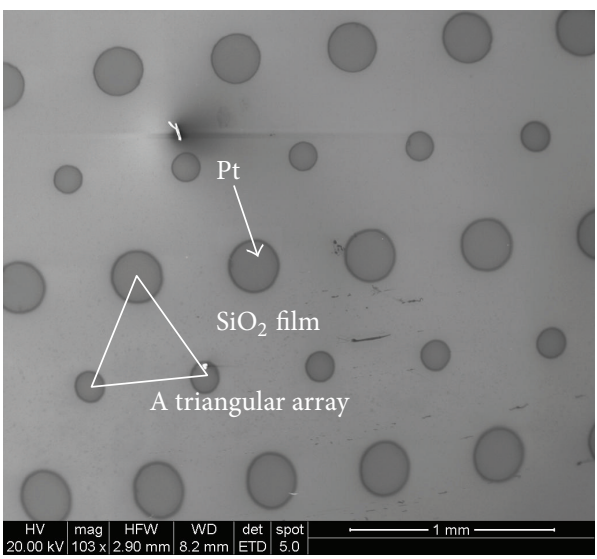

(a)

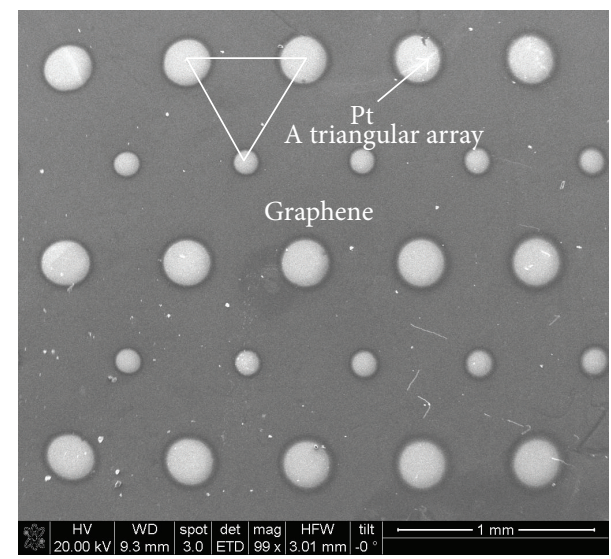

(b)

Figure 1: Surface morphologies of a triangular array of Pt cylinders on (a) $\mathrm{SiO}_{2} / \mathrm{Si}$ substrate and (b) graphene/SiO$/ 2 / \mathrm{Si}$.

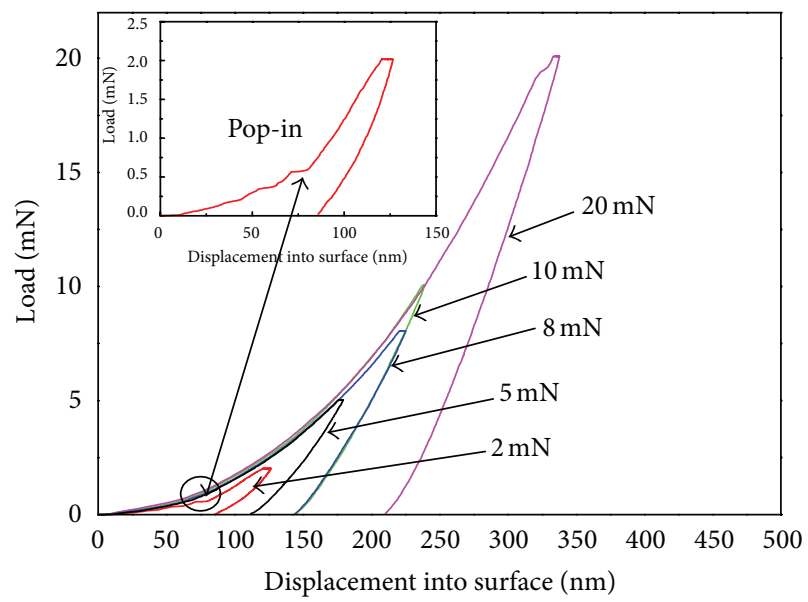

(a)

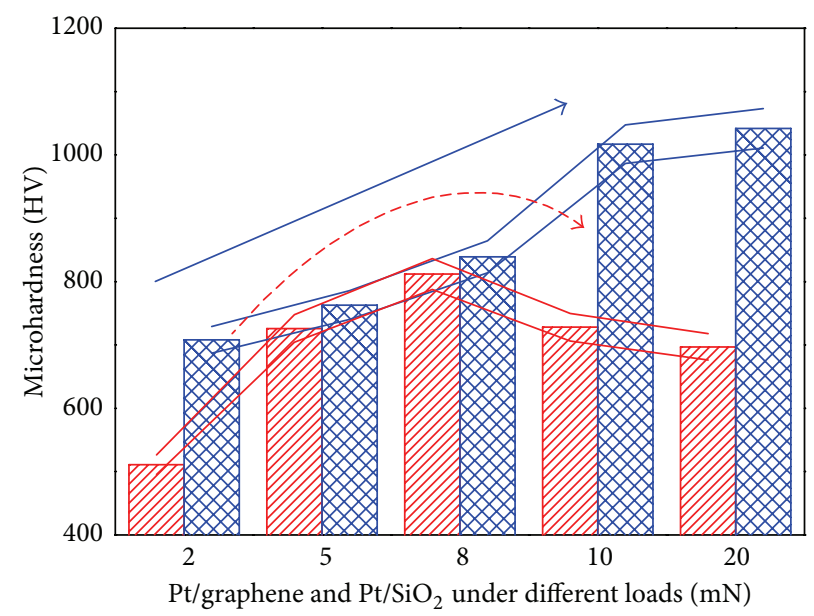

WII Pt/graph.

$\mathrm{Pt} / \mathrm{SiO}_{2}$

(c)

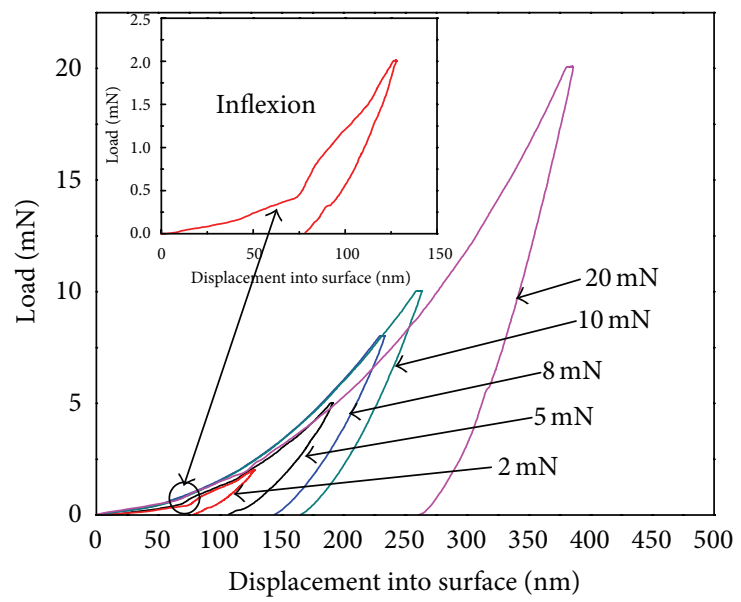

(b)

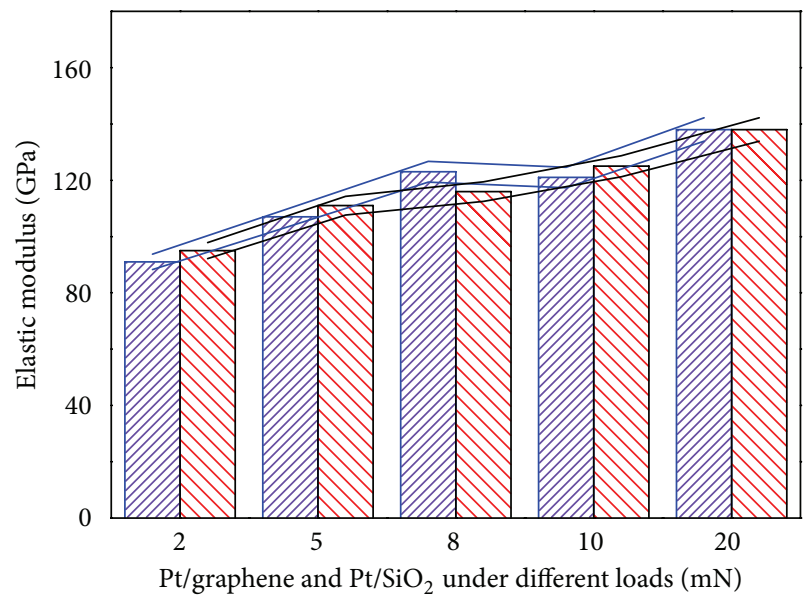

WII Pt/graph

MIV $\mathrm{Pt} / \mathrm{SiO}_{2}$

(d)

Figure 2: The loading-unloading curves of (a) $\mathrm{Pt} / \mathrm{SiO}_{2}$ and (b) $\mathrm{Pt} /$ graphene, respectively. (c) The microhardness and (d) elastic modulus with variations in the loads. 
shows the microhardness curves for the Pt/graphene and $\mathrm{Pt} / \mathrm{SiO}_{2}$ under different loads. This is to notice that the microhardness of the $\mathrm{Pt} /$ graphene increases with increasing load till the load of $8 \mathrm{mN}$; however, afterwards the microhardness gradually drops with the increase in the load. Because the indentation depth is found to be less than $230 \mathrm{~nm}$, ranging from the thickness of the Pt cylinder $(100 \mathrm{~nm})$ to $\mathrm{SiO}_{2}$ film $(300 \mathrm{~nm})$, effect of graphene on the support of Pt cylinder begins playing a role under the load of $8 \mathrm{mN}$, shown in the triangle of Figure 2(c). Recent research also confirms the finding that the graphene layer can carry higher loads than the $\mathrm{Pt}(111)$ surface at similar penetration depths [15]. On the contrary, the microhardness of the $\mathrm{Pt} / \mathrm{SiO}_{2}$ increases with the increase of the load and finally reaches a nearly constant value when a load of $10 \mathrm{mN}$ or higher is applied. It can be observed from Figure 2(c) that the hardness gradually increases with increase in load and till a load of $10 \mathrm{mN}$ which afterwards becomes almost constant. Moreover, the indentation depth is in the range of the thickness of 250$300 \mathrm{~nm}$, which corresponds to the thickness of $\mathrm{SiO}_{2}$ film on $\mathrm{Si}$ substrate. Thus, to some extent, the microhardness of $\mathrm{Pt} / \mathrm{SiO}_{2}$ may be affected by $\mathrm{SiO}_{2}$ film with the thickness of $300 \mathrm{~nm}$. According to the above analysis, these findings reveal that even a thin layer of graphene (less than $1 \mathrm{~nm}$ ) can act as an effective support material which can be attributed to its high compressive strength.

The elastic moduli of the $\mathrm{Pt} /$ graphene and $\mathrm{Pt} / \mathrm{SiO}_{2}$ are shown in Figure 2(d). The elastic modulus of both $\mathrm{Pt} / \mathrm{SiO}_{2}$ and $\mathrm{Pt} /$ graphene gradually increases as the load increases. However, Pt/graphene exhibits higher elastic modulus than $\mathrm{Pt} / \mathrm{SiO}_{2}$ does until the load of $8 \mathrm{mN}$. Here, the loading displacement is less than $220 \mathrm{~nm}$. The results show that the interface between $\mathrm{Pt}$ and graphene and graphene and $\mathrm{SiO}_{2}$ film will affect the change in the elastic modulus of $\mathrm{Pt} /$ graphene and could be attributed to the effect of graphene due to its high strength and large elastic modulus [16]. This is to observe that the elastic modulus of $\mathrm{Pt} / \mathrm{SiO}_{2}$ rapidly increases when loaded under $20 \mathrm{mN}$ and approaches that of $\mathrm{Pt}$ /graphene.

From the above findings, it follows that graphene as a middle layer between $\mathrm{Pt}$ and $\mathrm{SiO}_{2}$ film can have an important influence on the microhardness and the elastic modulus. When the indenter comes into contact with graphene, the carbon network of graphene provides a thin support layer for Pt cylinders until the frame is broken. Therefore, the present nanoindentation provides a potential approach for evaluating the effect of graphene as a middle layer on interface between $\mathrm{Pt}$ and $\mathrm{SiO}_{2}$ film.

\subsection{Interaction Effects between Graphene and Pt Cylinder-} Array Structure. In order to reveal the effect of graphene on formation mechanisms of $\mathrm{Pt}$ cylinders on the $\mathrm{SiO}_{2}$ film and graphene surfaces, it is necessary to investigate the surface characteristics of two samples. Figures 3(a) and 3(b) show the water contact angle (WCA) of the $\mathrm{SiO}_{2} / \mathrm{Si}$ substrate and the graphene $/ \mathrm{SiO}_{2} / \mathrm{Si}$. This, respectively, is $47.2^{\circ}$ and $76.1^{\circ}$ for $\mathrm{SiO}_{2} / \mathrm{Si}$ and the graphene, which indicates that the $\mathrm{SiO}_{2} / \mathrm{Si}$ substrate is more prone to wetting than graphene $/ \mathrm{SiO}_{2} / \mathrm{Si}$. Figure 4 illustrates the schematic diagram of $\mathrm{Pt}$ cylinders

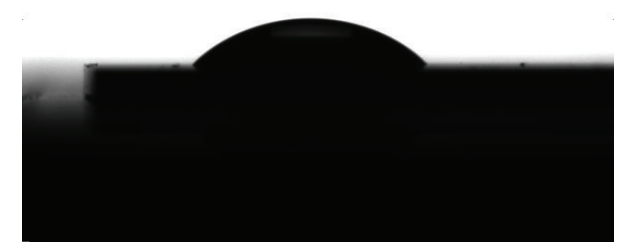

(a)

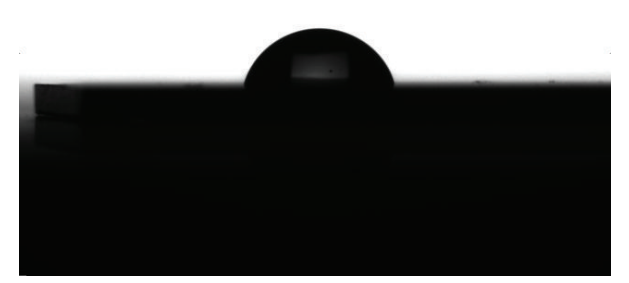

(b)

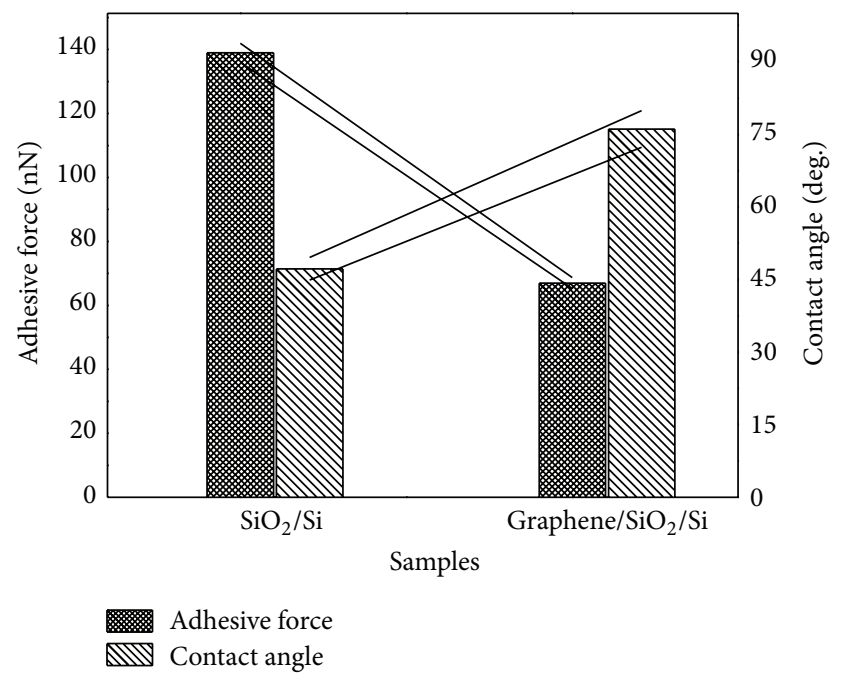

(c)

FIgURE 3: The contact angle of (a) $\mathrm{SiO}_{2} / \mathrm{Si}$ substrate and (b) the graphene $/ \mathrm{SiO}_{2} / \mathrm{Si}$ substrate and (c) the comparative value of the adhesive force and contact angle between them.

formation process. From Figures 4(a) and 4(b), we can clearly see that Pt atoms grow as a planar structure and absorb into the surface of $\mathrm{SiO}_{2} / \mathrm{Si}$ substrate due to its better wettability, but Pt cylinders keep a weak cohesion with $\mathrm{SiO}_{2} / \mathrm{Si}$ substrate due to Van der Waals forces [7]. Relatively, Pt cylinders grow as a shell structure on graphene $/ \mathrm{SiO}_{2} / \mathrm{Si}$ because of the existence of a wrinkle in graphene, as schematized in Figures 4(c) and 4(d) and reported in theoretical studies [17]. This shrinkage may result from easily noticeable folded regions 


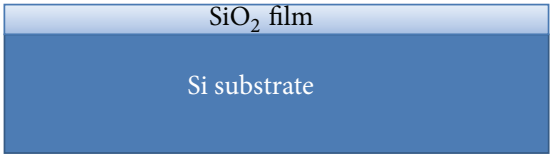

(a)

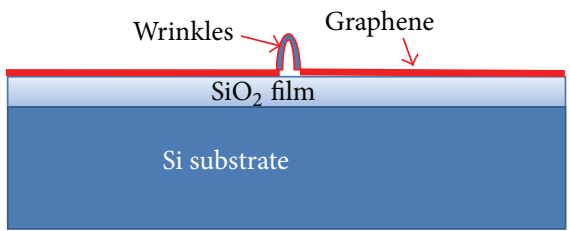

(c)

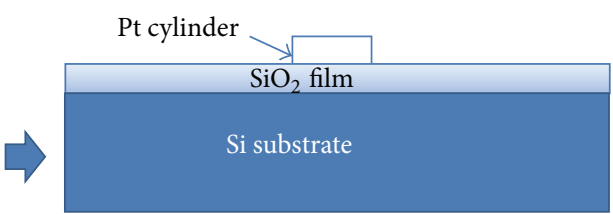

(b)

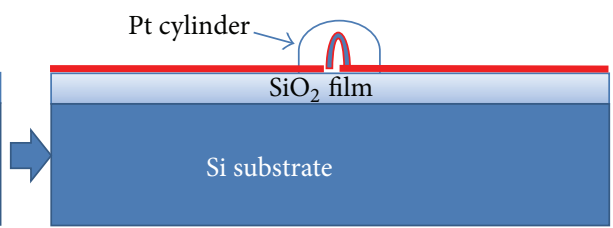

(d)

Figure 4: The schematic diagrams of (a) $\mathrm{SiO}_{2} / \mathrm{Si}$ substrate, (b) Pt cylinders grown on $\mathrm{SiO}_{2} / \mathrm{Si}$, (c) graphene/SiO $2 / \mathrm{Si}$, and (d) Pt cylinders grown on the graphene $/ \mathrm{SiO}_{2} / \mathrm{Si}$, respectively.

as well as from the evolution of dendritic wrinkles, which can affect the growth of $\mathrm{Pt}$ cylinders on graphene $/ \mathrm{SiO}_{2} / \mathrm{Si}$ thus causing reduction in adhesive force: compare $139 \mathrm{nN}$ of $\mathrm{SiO}_{2} / \mathrm{Si}$ with $67 \mathrm{nN}$ of graphene/ $/ \mathrm{SiO}_{2} / \mathrm{Si}$. The results reported in Figures 3 and 4 demonstrate that the adhesion forces decrease with increasing contact angles, a finding in good agreement with $[7,18]$.

3.3. Effect of Graphene as a Middle Layer on Friction and Wear of $\mathrm{SiO}_{2} / \mathrm{Si}$ Substrate. In view of the above results, the effect of graphene as a middle layer between $\mathrm{Pt}$ and $\mathrm{SiO}_{2}$ film on the macrotribological properties was investigated. The friction and wear tests were performed on $\mathrm{Pt} /$ graphene and $\mathrm{Pt} / \mathrm{SiO}_{2}$ using a ball-on-plate tribometer and under the load of $0.1 \mathrm{~N}$. Figure 5 shows friction behavior of both films. The COF of both $\mathrm{Pt} /$ graphene and $\mathrm{Pt} / \mathrm{SiO}_{2}$ is less than 0.2 before $1300 \mathrm{~s}$. Subsequently, the COF of $\mathrm{Pt} / \mathrm{SiO}_{2}$ sharply increases from 0.2 to 1.0. However, that of $\mathrm{Pt} /$ graphene remains almost stable to 0.2 . Moreover, its wear lifetime is higher than $3500 \mathrm{~s}$ which is twice that of $\mathrm{Pt} / \mathrm{SiO}_{2}$. In fact, for $\mathrm{Pt} / \mathrm{SiO}_{2}, \mathrm{Pt}$ cylinders due to its low hardness can easily be destroyed and extrude outside the wear track. During wear test, only a part of Pt cylinders are transferred to the surface of the steel ball. Simultaneously, the friction occurs between the $\mathrm{SiO}_{2}$ film and the steel ball partly covered with Pt. The COF of $\mathrm{Pt} / \mathrm{SiO}_{2}$ is affected by $\mathrm{Pt}$ due to its low shear strength. As can be seen from Figure 6(a), there is significant wear/scratch damage on the $\mathrm{SiO}_{2} / \mathrm{Si}$ substrate. As for Pt/graphene, Pt cylinders act as very strong pinning centers for the sliding of graphene sheets, which had certain pinning effects on graphene sheets and prevented graphene sheets from sliding. Before the Pt cylinder array was rubbed, $\mathrm{Pt}$ with the low shear strength can be a lubricating medium and reduces the friction. As indicated in Figure 6(b), after the spoiled Pt extrudes outside the wear track, the friction occurs between graphene and steel counterface covered with $\mathrm{Pt}$ transferring films. Although Pt cylinders are easily ploughed or destroyed, the unspoiled Pt cylinders can still remain on the graphene surface. Hence, due to the fact that graphene as a middle layer supports the unspoiled Pt cylinders to prevent

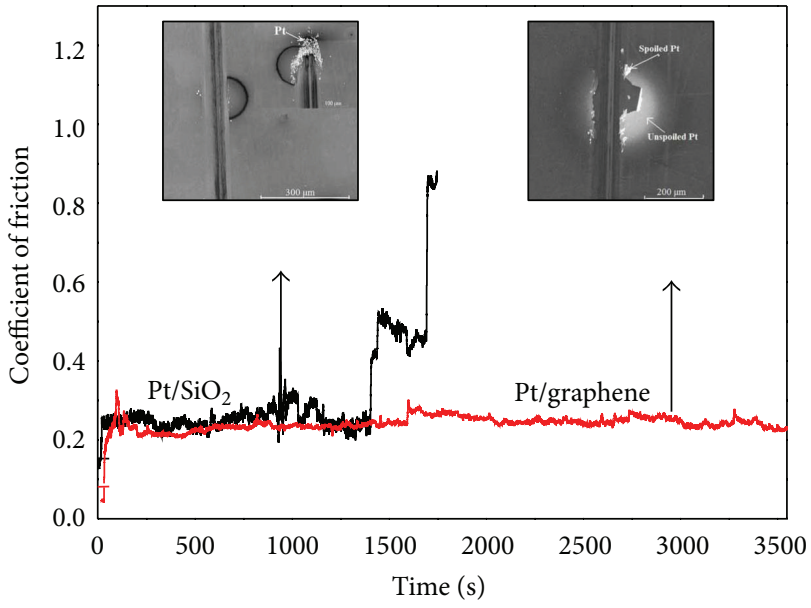

FIgure 5: Comparison of friction coefficient of both $\mathrm{Pt} / \mathrm{SiO}_{2}$ and $\mathrm{Pt} /$ graphene against steel balls under the load of $0.1 \mathrm{~N}$.

the direct contact between the $\mathrm{SiO}_{2} / \mathrm{Si}$ substrate and steel counterface [19], Pt/graphene has a certain role in reducing the friction and improving the wear lifetime.

On the one hand, as for the worn surfaces of $\mathrm{Pt} / \mathrm{SiO}_{2}$ substrate in Figure 6(a), the Raman spectrum presented in Figure 7 indicates that there are no obvious D and $G$ bands on the wear track. Further, the typical Si peaks at $520 \mathrm{~cm}^{-1}$ and $964 \mathrm{~cm}^{-1}$ can be observed at the center of the wear track which reveals that the spoiled Pt cylinders during wear test extruded outside the wear track thus exposing the $\mathrm{SiO}_{2} / \mathrm{Si}$ substrate.

On the other hand, as observable from Figure 6(b), a continuous and compact film forms on the wear track on the Pt/graphene. This is to notice from the Raman spectrum, shown in Figure 7, taken at the center of the wear track, that graphene contrary to $\mathrm{SiO}_{2} / \mathrm{Si}$ did not extrude on the two sides of the wear track, and also there are obvious D and G bands at the center of the wear track. The intensity ratio of a $D$ band to that of a G band $\left(I_{\mathrm{d}} / I_{\mathrm{g}}\right)$ is around 1.1. $I_{\mathrm{d}} / I_{\mathrm{g}}$ is related to the 


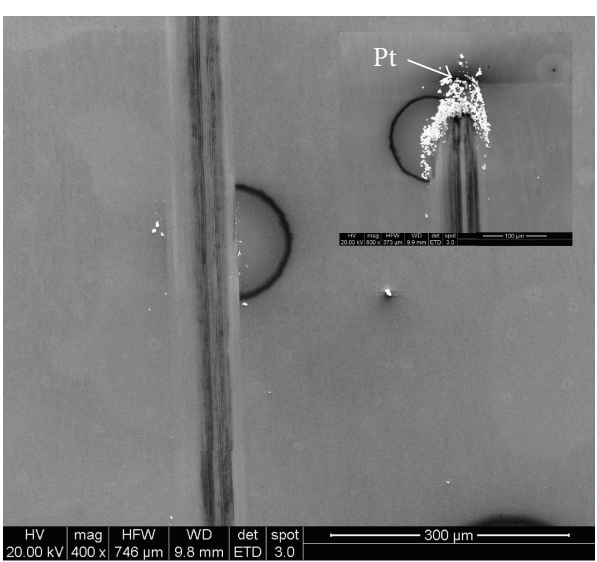

(a)

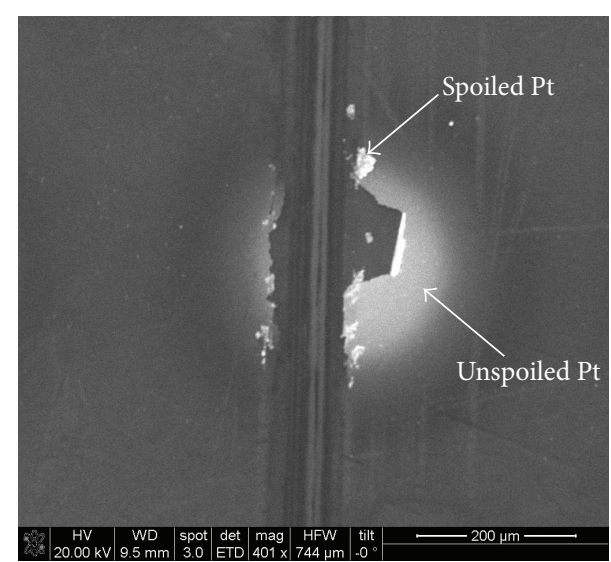

(b)

Figure 6: The worn morphologies of (a) $\mathrm{Pt} / \mathrm{SiO}_{2}$ substrate and (b) $\mathrm{Pt} /$ graphene.

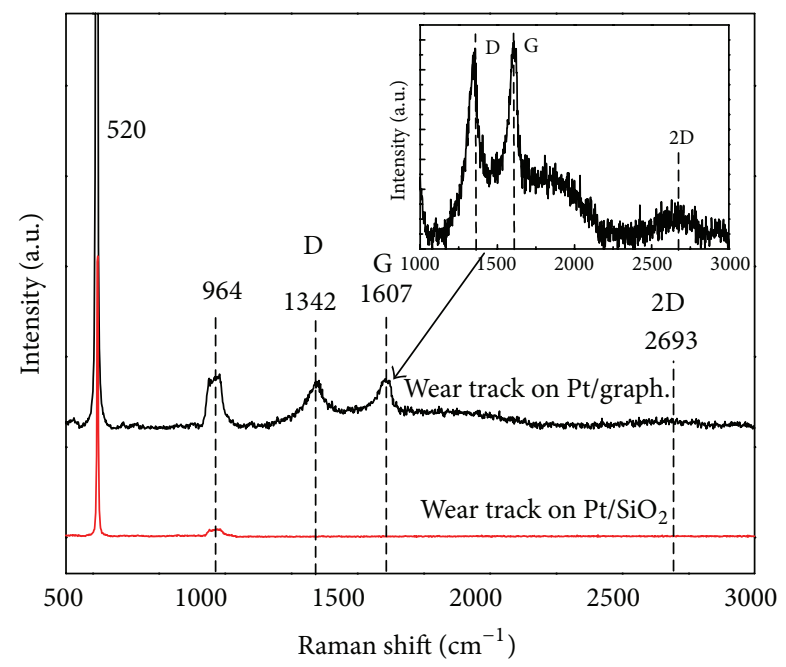

Figure 7: Raman spectra of both $\mathrm{Pt} / \mathrm{SiO}_{2}$ substrate and $\mathrm{Pt} /$ graphene/ $/ \mathrm{SiO}_{2}$ at the center of the wear track after the friction and wear.

changes in the microstructure of graphene surface because it correlates with the $\mathrm{sp}^{3} / \mathrm{sp}^{2}$ bonding ratio and the size of graphite clusters [20]. Moreover, it can be observed that there is $2 \mathrm{D}$ band at $\sim 2700 \mathrm{~cm}^{-1}$, which is regarded as a function of the number of layers. A further increase of the number of layers leads to a significant decrease in the relative intensity of the lower frequency 2D peaks. Therefore, during the friction and wear process, surface states of graphene greatly changed, including defects and composition. Graphene surface oxidation further decreases its surface energy and wear resistance. The interaction between graphene and Pt cylinders prolongs the wear lifetimes.

\section{Conclusions}

Periodic arrays of Pt cylinders were prepared using magnetron sputtering technology onto $\mathrm{SiO}_{2} / \mathrm{Si}$ substrates and also on graphene which was previously deposited onto a $\mathrm{SiO}_{2} / \mathrm{Si}$ substrate. The effects of graphene as an adhesive layer on macrotribological properties of $\mathrm{Pt} / \mathrm{SiO}_{2}$ were investigated. The results indicated that the Pt cylinders can play a significant role in decreasing the friction, but graphene as a middle layer enhances the interaction between Pt cylinders and $\mathrm{SiO}_{2}$ film. Therefore, $\mathrm{Pt} / \mathrm{graphene}$ does not offer only a low friction coefficient; but it also prolongs the wear lifetime. This study can serve as novel approach to improve the macrotribological behavior of $\mathrm{SiO}_{2} / \mathrm{Si}$ substrate.

\section{Conflict of Interests}

The authors declare that there is no conflict of interests regarding the publication of this paper.

\section{Acknowledgments}

This project was supported by the Project Funded by the Priority Academic Program Development of Jiangsu Higher Education Institution, the Funds of National Natural Science Foundation of China (no. 51405242), the Natural Science Foundation of Jiangsu Province of China (no. BK2012463), and Jiangsu Government Scholarship for Overseas Studies.

\section{References}

[1] O. Penkov, H.-J. Kim, H.-J. Kim, and D.-E. Kim, “Tribology of graphene: a review," International Journal of Precision Engineering and Manufacturing, vol. 15, no. 3, pp. 577-585, 2014.

[2] M. Amrita, R. R. Srikant, and A. V. Sitaramaraju, "Performance evaluation of nanographite-based cutting fluid in machining process," Materials and Manufacturing Processes, vol. 29, no. 5, pp. 600-605, 2014.

[3] T. M. Mayer, J. W. Elam, S. M. George, P. G. Kotula, and R. S. Goeke, "Atomic-layer deposition of wear-resistant coatings for microelectromechanical devices," Applied Physics Letters, vol. 82, no. 17, pp. 2883-2885, 2003.

[4] D. P. Hunley, T. J. Flynn, T. Dodson, A. Sundararajan, M. J. Boland, and D. R. Strachan, "Friction, adhesion, and elasticity 
of graphene edges," Physical Review B, vol. 87, no. 3, Article ID 035417, 2013.

[5] Q. Wang, B. Bai, Y. Li, Y. Jiang, L. Ma, and N. Ren, "Investigating the nano-tribological properties of chemical vapor depositiongrown single layer graphene on $\mathrm{SiO}_{2}$ substrates annealed in ambient air," RSC Advances, vol. 5, no. 13, pp. 10058-10064, 2015.

[6] C. Lee, Q. Li, W. Kalb et al., "Frictional characteristics of atomically thin sheets," Science, vol. 328 , no. 5974, pp. 76-80, 2010.

[7] J. F. Ou, J. Q. Wang, S. L. Liu et al., “Tribology study of reduced graphene oxide sheets on silicon substrate synthesized via covalent assembly," Langmuir, vol. 26, no. 20, pp. 1583015836, 2010.

[8] H. Y. Wu, Z. B. Gu, C. J. Gong et al., "Macrotribological behavior of the graphene surface structured in a cylinder array," Surface and Coatings Technology, vol. 236, no. 15, pp. 296-302, 2013.

[9] A. Ababneh, A. N. Al-Omari, M. Marschibois et al., "Investigations on the high temperature compatibility of various adhesion layers for platinum," in Smart Sensors, Actuators, and MEMS VI, 87631Z, vol. 8763 of Proceedings of SPIE, p. 6, Grenoble, France, May 2013.

[10] F. G. Sen, Y. Qi, and A. T. Alpas, "Anchoring platinum on graphene using metallic adatoms: a first principles investigation," Journal of Physics Condensed Matter, vol. 24, no. 22, Article ID 225003, 2012.

[11] K. Okazaki-Maeda, Y. Morikawa, S. Tanaka, and M. Kohyama, "Structures of Pt clusters on graphene by first-principles calculations," Surface Science, vol. 604, no. 2, pp. 144-154, 2010.

[12] X. M. Liu, F. P. Yuan, and Y. G. Wei, "Grain size effect on the hardness of nanocrystal measured by the nanosize indenter," Applied Surface Science, vol. 279, no. 15, pp. 159-166, 2013.

[13] W. C. Oliver and G. M. Pharr, "Improved technique for determining hardness and elastic modulus using load and displacement sensing indentation experiments," Journal of Materials Research, vol. 7, no. 6, pp. 1564-1583, 1992.

[14] M. Cabibbo, D. Ciccarelli, and S. Spigarelli, "Nanoindentation hardness measurement in piling up $\mathrm{SiO}_{2}$ coating," Physics Procedia, vol. 40, pp. 100-112, 2013.

[15] A. Klemenz, L. Pastewka, S. G. Balakrishna, A. Caron, R. Bennewitz, and M. Moseler, "Atomic scale mechanisms of friction reduction and wear protection by graphene," Nano Letters, vol. 14, no. 12, pp. 7145-7152, 2014.

[16] S. L. Ye, H. H. Huang, C. L. Yuan et al., “Thickness-dependent strain effect on the deformation of the graphene-encapsulated Au nanoparticles," Journal of Nanomaterials, vol. 2014, Article ID 989672, 6 pages, 2014.

[17] M. J. Lee, J. S. Choi, J.-S. Kim et al., "Characteristics and effects of diffused water between graphene and $\mathrm{SiO}_{2}$ substrate," Nano Research, vol. 5, no. 10, pp. 710-717, 2012.

[18] S. L. Ren, S. R. Yang, and Y. P. Zhao, "Micro- and macrotribological study on a self-assembled dual-layer film," Langmuir, vol. 19, no. 7, pp. 2763-2767, 2003.

[19] Y. C. Xin, J.-G. Liu, Y. Zhou et al., "Preparation and characterization of Pt supported on graphene with enhanced electrocatalytic activity in fuel cell," Journal of Power Sources, vol. 196, no. 3, pp. 1012-1018, 2011.

[20] A. C. Ferrari, "Raman spectroscopy of graphene and graphite: disorder, electron-phonon coupling, doping and nonadiabatic effects," Solid State Communications, vol. 143, no. 1-2, pp. 47-57, 2007. 

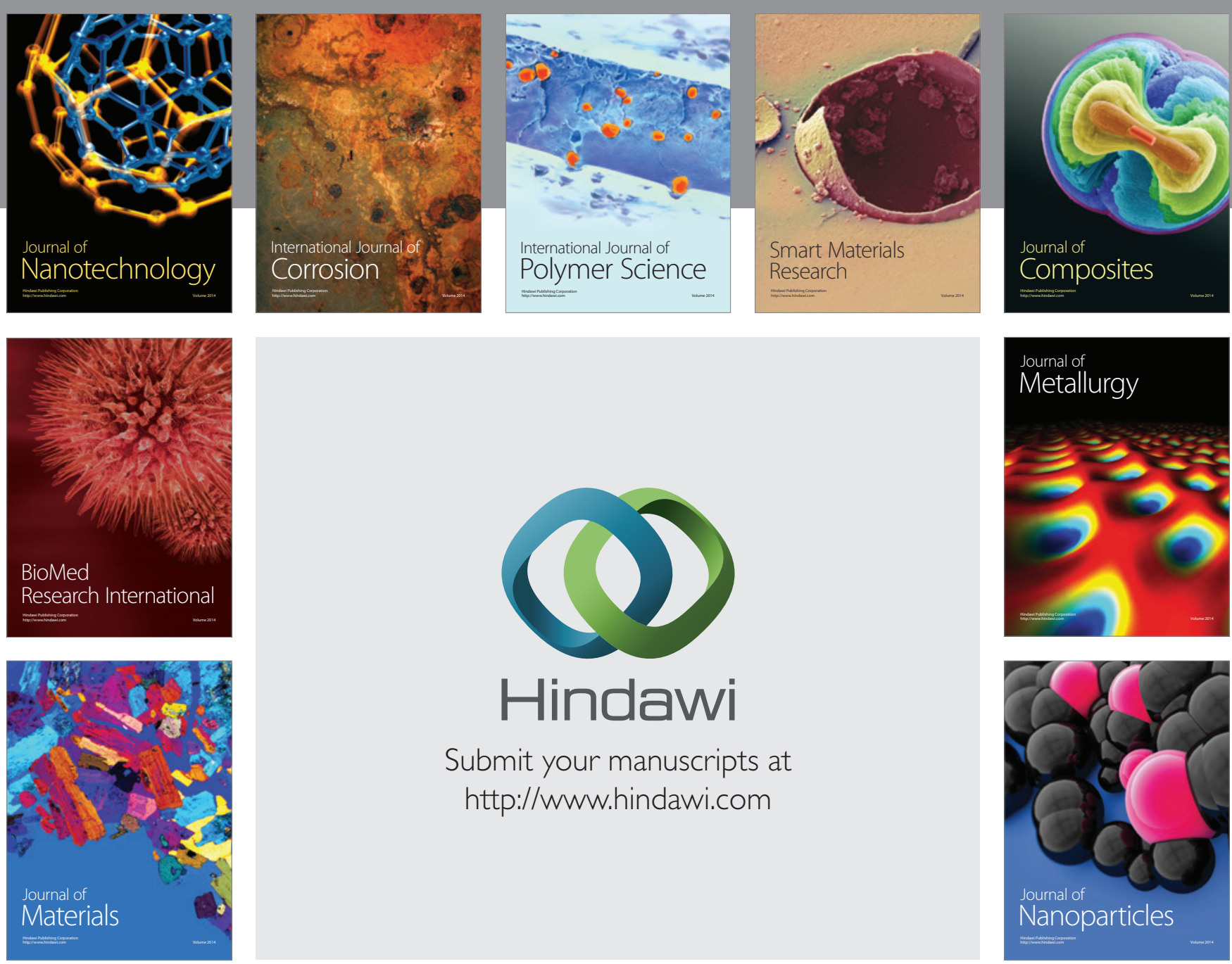

Submit your manuscripts at http://www.hindawi.com
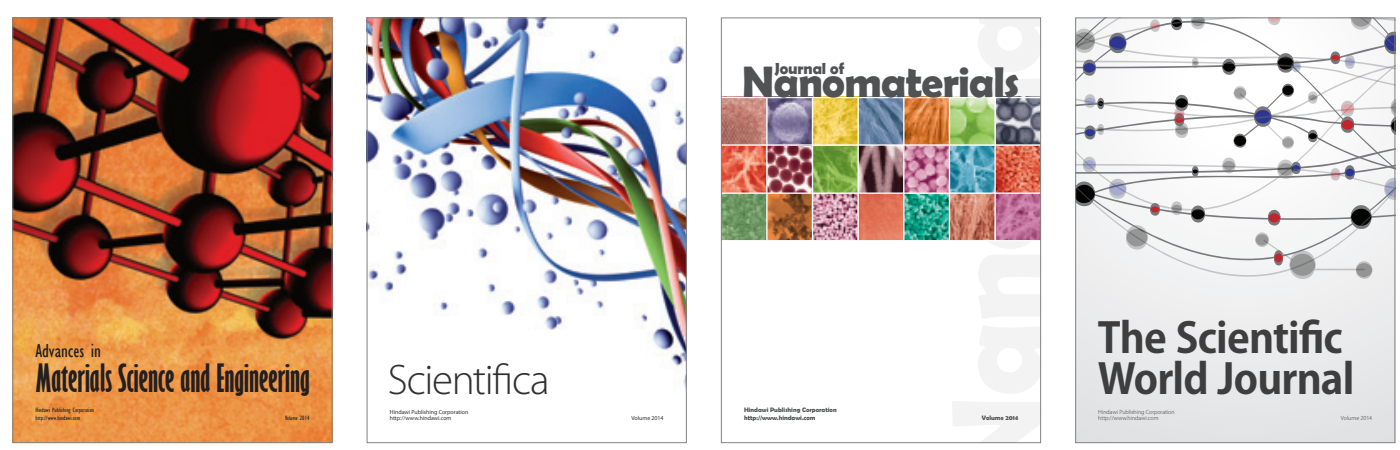

\section{The Scientific World Journal}
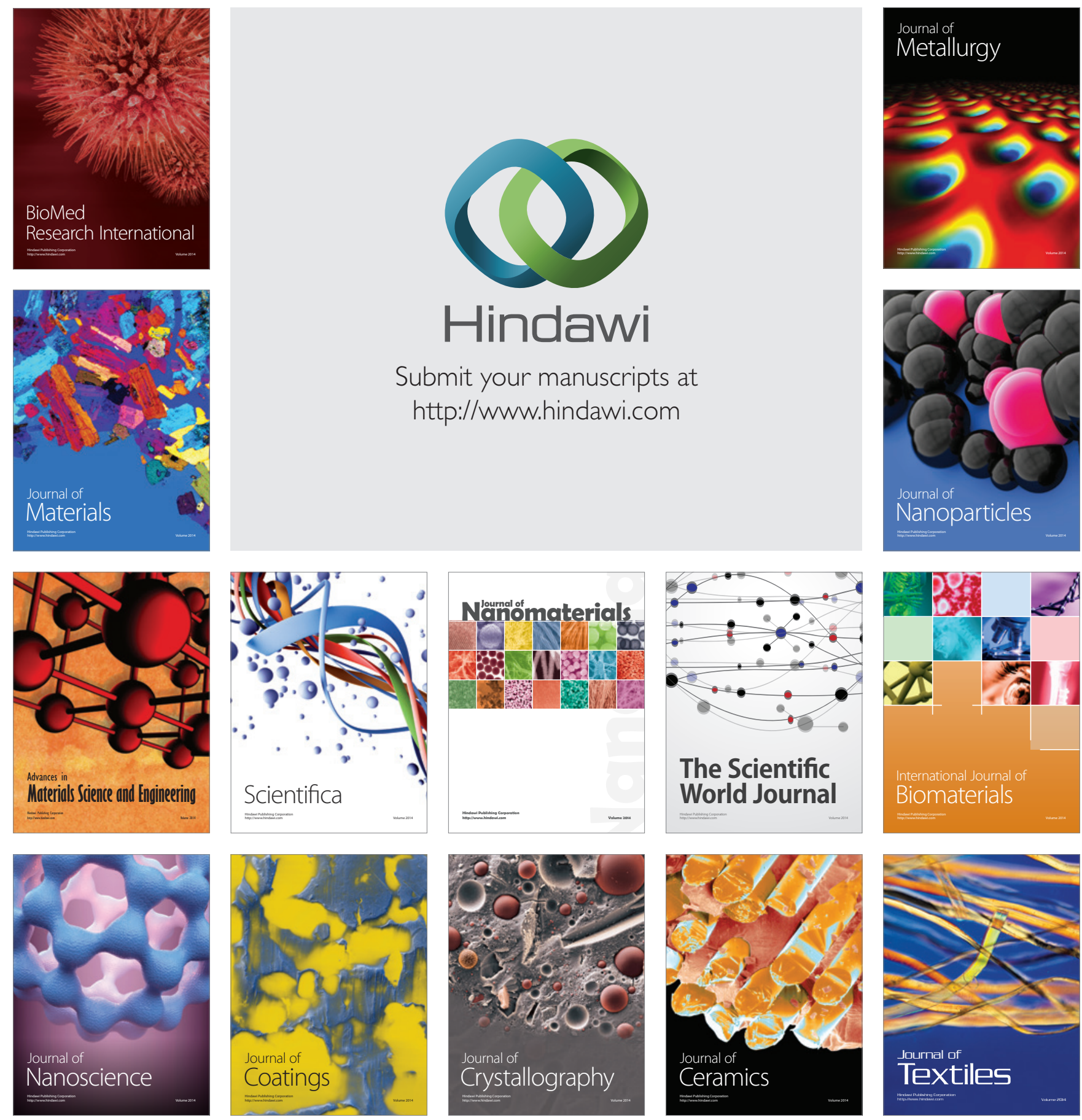